University of Nebraska - Lincoln

DigitalCommons@University of Nebraska - Lincoln

Papers in Veterinary and Biomedical Science

Veterinary and Biomedical Sciences, Department of

$8-1-2013$

\title{
Osmotic Stress, not Aldose Reductase Activity, Directly induces Growth Factors and MAPK Signaling changes during Sugar Cataract Formation
}

Peng Zhang

Kuiyi Xing

James Randazzo

Karen Blessing

Marjorie F. Lou

See next page for additional authors

Follow this and additional works at: https://digitalcommons.unl.edu/vetscipapers

Part of the Biochemistry, Biophysics, and Structural Biology Commons, Cell and Developmental

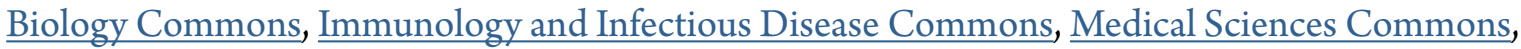
Veterinary Microbiology and Immunobiology Commons, and the Veterinary Pathology and Pathobiology Commons

This Article is brought to you for free and open access by the Veterinary and Biomedical Sciences, Department of at DigitalCommons@University of Nebraska - Lincoln. It has been accepted for inclusion in Papers in Veterinary and Biomedical Science by an authorized administrator of DigitalCommons@University of Nebraska - Lincoln. 
Authors

Peng Zhang, Kuiyi Xing, James Randazzo, Karen Blessing, Marjorie F. Lou, and Peter Kador 


\title{
Osmotic Stress, not Aldose Reductase Activity, Directly induces Growth Factors and MAPK Signaling changes during Sugar Cataract Formation
}

\author{
Peng Zhang ${ }^{1}$, Kuiyi Xing ${ }^{2}$, James Randazzo ${ }^{1}$, Karen Blessing ${ }^{1}$, Marjorie F. Lou ${ }^{2,3}$, and \\ Peter F. Kador ${ }^{1,2,3}$ \\ ${ }^{1}$ Department of Pharmaceutical Sciences, College of Pharmacy, University of Nebraska Medical \\ Center, Omaha, NE \\ ${ }^{2}$ School of Veterinary Medicine and Biomedical Sciences, University of Nebraska at Lincoln, \\ Lincoln, NE \\ ${ }^{3}$ Department of Ophthalmology, School of Medicine, University of Nebraska Medical Center, \\ Omaha, NE
}

\begin{abstract}
In sugar cataract formation in rats, aldose reductase (AR) actitvity is not only linked to lenticular sorbitol (diabetic) or galactitol (galactosemic) formation but also to signal transduction changes, cytotoxic signals and activation of apoptosis. Using both in vitro and in vivo techniques, the interrelationship between AR activity, polyol (sorbitol and galactitol) formation, osmotic stress, growth factor induction, and cell signaling changes have been investigated. For in vitro studies, lenses from Sprague Dawley rats were cultured for up to $48 \mathrm{hrs} \mathrm{in} \mathrm{TC-199-bicarbonate} \mathrm{media}$ containing either $30 \mathrm{mM}$ fructose (control), or $30 \mathrm{mM}$ glucose or galctose with/without the aldose reductase inhibitors AL1576 or tolrestat, the sorbitol dehydrogenase inhibitor (SDI) CP-470,711, or $15 \mathrm{mM}$ mannitol (osmotic-compensated media). For in vivo studies, lenses were obtained from streptozotocin-induced diabetic Sprague Dawley rats fed diet with/without the ARIs AL1576 or tolrestat for 10 weeks. As expected, lenses cultured in high glucose / galactose media or from untreated diabetic rats all showed a decrease in the GSH pool that was lessened by ARI treatment. Lenses either from diabetic rats or from glucose/galactose culture conditions showed increased expression of basic-FGF, TGF- $\beta$, and increased signaling through P-Akt, P-ERK1/2 and P-SAPK/ JNK which were also normalized by ARIs to the expression levels observed in non-diabetic controls. Culturing rat lenses in osomotically compensated media containing $30 \mathrm{mM}$ glucose or galactose did not lead to increased growth factor expression or altered signaling. These studies indicate that it is the biophysical response of the lens to osmotic stress that results in an increased intralenticular production of basic-FGF and TGF- $\beta$ and the altered cytotoxic signaling that is observed during sugar cataract formation.
\end{abstract}

\footnotetext{
(C) 2012 Elsevier Ltd. All rights reserved.

Present Address Corresponding Author, Peter F. Kador, Ph.D., FARVO, College of Pharmacy, 986025 Nebraska Medical Center, Omaha, NE 68198-6025, pkador@unmc.edu.

Publisher's Disclaimer: This is a PDF file of an unedited manuscript that has been accepted for publication. As a service to our customers we are providing this early version of the manuscript. The manuscript will undergo copyediting, typesetting, and review of the resulting proof before it is published in its final citable form. Please note that during the production process errors may be discovered which could affect the content, and all legal disclaimers that apply to the journal pertain.
} 


\section{Keywords}

diabetes; lens; cataracts; in vitro lens culture; aldose reductase inhibitors; sorbitol dehydrogenase inhibitors; iso-osmotic culture; growth factors; b-FGF; TGF- $\beta$; cell signaling; P-42/44 MAPK; PSAPK/JNK; P-Akt

\section{Introduction}

Cataracts in diabetic or galactosemic animals are directly linked to the aldose reductase (AR) catalyzed accumulation of sorbitol from glucose or galactitol from galactose. Excess accumulation of these polyols (sorbitol or galactitol) initiates osmotic stress that alters lens cell permeability, decreases ATPase activity, decreases crystallin synthesis, reduces amino acid uptake and alters redox homeostasis (Cheng and Gonzalez, 1986; Kador, 1994; Kinoshita, 1974; Lee and Chung, 1999). Osmotic stress can also initiate endoplasmic reticulum (ER) stress that induces an unfolded protein response (UPR) which results in oxidative stress through the formation of reactive oxygen species (ROS) and apoptosis (Mulhern et al., 2006; Zhang et al., 2009) . AR activity is primarily located in the metabolically active epithelial cell layer and the differentiating epithelial cells at the equatorial region (Akagi et al., 1987; Akagi et al., 1988; Akagi et al., 1986; Akagi et al., 1984). These cells contain mitochondria that can participate in the UPR. Lens epithelial cells also possess receptors to basic fibroblast growth factor (bFGF) and transforming growth factor- $\beta$ (TGF- $\beta$ ). All of these growth factors can alter lens physiology (He et al., 2007; Ibaraki et al., 1995, 1996; Kampmeier et al., 2006; Schneider et al., 2010).

Binding of bFGF or TGF- $\beta$ to lens cell surface receptors initiates cell signaling pathways that include the MAPK/ERK signal transduction pathway. MAPKs comprise a family of ubiquitous proline-directed, protein-serine/threonine kinases, including c-Jun N-terminal kinases/stress-activated protein kinases (JNK/SAPKs), extracellular signal-regulated kinases 1 and 2 (ERK1 and ERK2), c-Raf, and p38 Pathways, which are activated by phosphorylation cascades and respond to extracellular stimuli (mitogens) and regulate various cellular activities, such as gene expression, mitosis, differentiation, proliferation, and cell survival/apoptosis (Pearson et al., 2001). All MAPK pathways operate through sequential phosphorylation events to activate transcription factors and regulate gene expression.

Another important groups of molecules in cellular signaling is the Akt protein family which are located downstream of the phosphatidylinositol 3-kinases (PI3Ks) family of enzymes. The PI3K-Akt signaling pathway has been implicated in glucose metabolism, protein synthesis, receptor insertion, cytoskeletal reorganization and cell proliferation. However, Akts are most commonly associated with cell survival because they inhibit the activation of proapoptotic proteins and transcription factors (Aberg et al., 2003; Brazil et al., 2004).

Lens cells respond to outside stimuli through signal transduction which involves ordered sequences of biochemical reactions inside the cell in response to ligand binding or G-protein coupled receptors. Signaling changes in lens cells have been linked to the glucose-derived imbalance of metabolic homeostasis that occurs during diabetic cataract formation (Zatechka et al., 2003). AR activity has also been linked to signal transduction changes, cytotoxic signaling and activation of apoptosis. Exposure of cultured human epithelial cells to chronic hyperglycemia or the growth factor TNF-a causes cell death that is attenuated by inhibition of AR (Ramana et al., 2003). Inhibition of AR inhibition also prevents the activation of ERK1/2, JNK, and NF- $\mathrm{KB}$ in pig lens epithelial cells exposed to bFGF (Yadav et al., 2009). In diabetic rat lenses, ARIs also normalized the suppression of PI-3K and P- 
Raf-1 and increase of P-MEK, P-ERK, PPAK2, P-p38, and P-JNK (Zatechka et al., 2003). Pig lenses cultured in vitro in $30 \mathrm{mM}$ galactose also demonstrate activation of both the RafMEK-ERK and PI-3K-Akt pathways, and this activation is reduced by inhibition of AR (Zatechka and Lou, 2002). The observed signaling changes under both hyperglycemic and galactosemic conditions and their normalization by the presence of ARIs strongly suggest that these signaling changes are linked to AR activity. In this study, we have demonstrated that high glucose or galactose-induces bFGF and TGF $\beta$ expression in the lens and that the associated cell signaling responses can be controlled by ARI via the drug's ability to prevent osmotic stress.

\section{Material and Methods}

All procedures involving live animals were performed in accordance with the National Institutes of Health Guide for the Care and Use of Laboratory Animals and the Association for Research in Vision and Ophthalmology Statement for the Use of Animals in Ophthalmic and Vision Research under protocol 05-102-01 approved by the University of Nebraska Medical Center Institutional Animal Care and Use Committee (IACUC).

Three-week-old (100 g) male Sprague-Dawley rats were purchased from the Sasco Division of Charles River Laboratories (Wilmington, MA). Spiro-(2,7-difluoro-7H-fluorene-9,4' imidazolidine) $-2^{\prime}-5^{\prime}$-dione (AL1576) was obtained from Alcon Laboratories (Fort Worth, TX) and tolrestat ( $N$-[(5-trifluoromethyl-6-methoxy-1-naphthalenyl)thioxomethyl]- $N$ methyl-glycine) was obtained from Wyeth-Ayerst Laboratories (Princeton, NJ). The SDI CP-166,572 (4-[4-( $N, N$-dimethylsulfamoyl)-piperazino]-2-hydroxymethylpyrimidine) was obtained from Pfizer Inc (Groton, CT). TC-199 medium (without phenol red indicator and glutamine) was supplied by the NIH media unit. All bFGF rabbit monoclonal antibody, TGF- $\beta$ rabbit monoclonal antibody and the phospho-Akt (Ser473) rabbit monoclonal antibody, phospho-ERK1/2 (phospho-44/42 MAPK) (Thr202/Tyr204) rabbit monoclonal antibody, phospho-SAPK/JNK monoclonal antibody and GAPDH rabbit monoclonal antibody were obtained from Cell Signaling Technologies (Beverly, MA). The enhanced chemiluminescence system components, including horseradish peroxidase (HRP) conjugated anti-rabbit antibody and chemiluminescent reagent were obtained from Cell Signaling Technologies (Beverly, MA). Electrophoretic materials all were obtained from Bio-Rad Laboratories (Hercules, CA). All other chemicals were of analytical grade.

\section{In vivo Diabetic Studies}

Diabetes was induced in young (100 g) Sprague Dawley rats by tail vein injection of $75 \mathrm{mg} /$ $\mathrm{kg}$ of streptozotocin (Kador et al., 2010a). All rats with blood glucose levels $>300 \mathrm{mg} / \mathrm{dl}$ were then equally divided into 3 groups of 8 each. The first diabetic group of 8 rats received standard rat diet (Bioserve, Frenchtown, NJ); the second diabetic group of 8 rats received similar rat diet containing $0.015 \%$ of tolrestat, the third diabetic group of 8 rats received similar diet containing 0.0125\% AL1576. Experimental diets were initiated 10 days following initial streptozotocin injections and continued for 10 weeks until the studies were terminated. Age-matched nondiabetic rats were used as controls. Blood glucose levels at the inset of the study were evaluated using a commercial glucometer (Freestyle by TheraSense, Alameda, CA) and HbA1C levels at the end of the study were measured using measured using a test kit (Bayer Metrika A1cNOW Plus System, San Diego, CA). Rats were killed by $\mathrm{CO}_{2}$ asphyxiation, their eyes were enucleated, and the lenses were surgically removed by posterior approach from the enucleated eyes. A minimum of 4 rats per group were used for Western Blot analysis. 


\section{Lenses Culture Studies}

Young $(100 \mathrm{~g})$ Sprague Dawley rats were asphyxiated with carbon dioxide. After death, the eyes were enucleated and the lens from each eye was removed by careful dissection from a posterior approach and incubated in sterile TC-199 - bicarbonate media containing $20 \mathrm{U} \mathrm{mL} /$ $\mathrm{L}$ of penicillin-streptomycin in a humidified incubator under an atmosphere of $95 \%$ air and $5 \% \mathrm{CO}_{2}$ at $37^{\circ}$ (Shiono et al., 1985). After $4 \mathrm{hr}$ each lens was examined under a dissecting microscope and each optically clear, intact (no capsular tear) lens was placed in 24-well culture plates containing $2 \mathrm{ml}$ of sterile TC-199 - bicarbonate media containing $20 \mathrm{U} \mathrm{mL} / \mathrm{L}$ of penicillin-streptomycin per well as follows: culture medium containing $30 \mathrm{mmol}$ fructose (control), culture medium containing $30 \mathrm{mmol} / \mathrm{l}$ glucose or galactose, culture medium containing $30 \mathrm{mmol} / \mathrm{l}$ glucose or galactose with $10 \mu \mathrm{M}$ AL1576, culture medium containing $30 \mathrm{mmol}$ glucose or galactose with $10 \mu \mathrm{M}$ tolrestat, culture medium containing $30 \mathrm{mmol}$ glucose or galactose with $10 \mu \mathrm{M}$ of the SDI CP-470,711, culture medium containing 30 $\mathrm{mmol} / \mathrm{l}$ glucose or galactose with $15 \mathrm{mM}$ mannitol. They were then cultured for up to $48 \mathrm{hr}$. At the end of the study each lens was examined for morphological changes and then removed from the culture dish, carefully blotted on wet filter paper, weighted, and then immediately frozen for subsequent analysis.

\section{Lens Polyol Levels}

Each lens was homogenized in a ground glass homogenizer and an aliquot of the homogenate was removed for colorimetric protein quantification using the DC Protein Assay (Bio-Rad Laboratories, Hercules, CA) and bovine serum albumin (BSA) protein standards. Three micromoles of xylitiol were added to each remaining homogenate as an internal standard and the homogenates were deproteinized by overnight centrifugation at $8^{\circ}$ $\mathrm{C}$ in Microcon YM-10 Centrifugal Filters. Each filtrate was dried in a Speedvac, and the residues were dissolved in $900 \mu \mathrm{L}$ of pyridine and derivatized with $900 \mu \mathrm{L}$ of phenyl isocyanate at $55^{\circ} \mathrm{C}$ for $60 \mathrm{~min}$. After cooling in an ice bath, cold methanol was added to each mixture followed by additional heating for $5 \mathrm{~min}$. The derivatized samples were analyzed by HPLC on an automated Hewlet Packard 1100 Chemstation equipped with a diode array detector. Samples $(5 \mu \mathrm{L})$ were injected onto a $150 \times 4.6 \mathrm{~mm}$ Tosoh TSK-GEL ODS-80Tm column containing a $3.2 \times 15 \mathrm{~mm}$ guard column at $35^{\circ} \mathrm{C}$. Samples were isocratically eluted with $20 \mathrm{mmol} / \mathrm{l}$ potassium phosphate/acetonitrile (35:65 v\%) buffer, $\mathrm{pH}$ 7.0 , at a flow rate of $1.0 \mathrm{ml} / \mathrm{min}$ and detected at $235 \mathrm{~nm}$. Samples were quantified against standard curve of sorbitol (0.008-6.0 $\mu \mathrm{moL})$.

\section{GSH Levels}

Each lens was homogenized in a ground glass homogenizer and the insoluble proteins were removed by centrifugation at $4^{\circ} \mathrm{C}$. Protein levels in an aliquot from each supernatant were measured according to Bradford Assay (Bradford, 1976). The remaining cell supernatants were then deproteinized with equal volumes of $20 \%$ TCA and GSH levels in the deproteinized supernatant were measured at $412 \mathrm{~nm}$ according to the DTNB method (Lou and Dickerson, 1992).

\section{PAGE and Western Immunoblot Analyses}

Each lens was homogenized in a ground glass homogenizer with ice cold lysis buffer (1\% NP-40, 0.5\% Deoxycholate, $1 \%$ SDS, $150 \mathrm{mmol} / \mathrm{L} \mathrm{NaCl}, 50 \mathrm{mmol} / \mathrm{L}$ Tris- $\mathrm{HCl}, \mathrm{pH}=8$ ) supplemented with a mixture of protease inhibitors (Cell Signaling Technology, USA). In soluble protein in each lens homogenate was removed by centrifugation in a microcentrifuge (14000 rpm, $30 \mathrm{~min}, 4^{\circ} \mathrm{C}$ ). Protein levels in the remaining supernatant were measured according to Bradford Assay (Bradford, 1976) and 50 micrograms of total protein from each rat lens homogenate was separated in precast linear $4-15 \%$ tris- $\mathrm{HCl}$ gradient polyacrylamide 
gel (Ready Gels, BIO-Rad, Hercules, CA). The separated proteins were electrophoretically transferred to nitrocellulose membrane, blocked with a 5\% powdered milk solution and washed with tris-buffered saline (TBS). The membranes were then separately incubated overnight at $4^{\circ}$ with antibodies against bFGF, TGF- $\beta$, Phospho-Akt, phospho-ERK1/2, and phospho-SAPK/JNK in accordance with the manufacturer's instructions. After final washings with $0.05 \%$ TBS-Tween, membranes bound antibody complexes were visualized by applying HRP conjugated anti-rabbit antibody to the membrane for $1 \mathrm{hr}$ at room temperature. The blots were again washed with TBS and processed for chemiluminescence detection of the immunoreactive proteins after incubation for $5 \mathrm{~min}$ at room temperature. Immunoreactive band densities were measured using Image-Pro Plus software (Bethesda, MD).

\section{Statistical Analysis}

Analyses were conducted with the ANOVA software on ProStat ver. 5.01 (Pearl River, NY) and Origin Pro 8.1 (OriginLab Corporation, Northampton, MA). All results with a $\mathrm{p} \leq$ $0.05 \%$ were considered to be significant.

\section{Results}

Tail vein injection of streptozotocin into young Sprague Dawley rats resulted in the induction of diabetes with all rats demonstrating blood glucose levels $>300 \mathrm{mg} / \mathrm{dL}$. Ten days after the induction of diabetes, select groups of the diabetic rats received rat chow containing either $0.015 \%$ tolrestat or $0.0125 \%$ AL1576. Consumption studies indicated that the diabetic rats ingested an average estimated dose (mean \pm S.D.) of $23.9 \pm 4.6 \mathrm{mg} / \mathrm{kg} /$ day for tolrestat and $16.4 \pm 0.9 \mathrm{mg} / \mathrm{kg} /$ day of AL1576. Glycosylated hemoglobin measurements conducted at the 10 week conclusion of the study demonstrated that all diabetic groups were equally hyperglycemic with mean $\mathrm{HbA1c}$ values $( \pm \mathrm{SD})$ of $10.95 \pm 0.36$ for untreated diabetic rats, $10.76 \pm 0.45$ for diabetic rats treated with tolrestat; and $10.48 \pm 0.86$ for diabetic rats treated with AL1576.

Lens opacities rapidly developed in all untreated diabetic rats with strong cortical to mature cataracts present by the end of the 10 week study. In contrast, only minor lens changes, primarily suture accentuation, developed in the tolrestat treated rats while no lens changes were observed in AL1576 treated rats. As anticipated, cataract formation correlated with increased sorbitol levels and reduced glutathione (GSH) levels which were normalized by AL1576 treatment but only partially increased by tolrestat where cataract formation was not fully arrested (Table 1). These observations correspond to previously published reports (Kador et al., 2000; Lou et al., 1988; Simard-Duquesne et al., 1985) and are presented only to demonstrate that the lenses subsequently analyzed conformed to established biochemical parameters associated with sugar cataract formation.

Lens changes associated with diabetic hyperglycemia can be reproduced by culturing intact lenses in medium containing $30 \mathrm{mM}$ sugars (Obazawa et al., 1974). To assess the effects of sorbitol formation in lenses, rat lenses were cultured for 24 and 48 hours in TC-199 bicarbonate culture media containing $30 \mathrm{mM}$ glucose with/without $10 \mu \mathrm{M}$ of the ARIs AL1576, tolrestat, $10 \mu \mathrm{M}$ of the SDI CP-166,572, or $15 \mathrm{mM}$ mannitol. Control lenses were cultured in TC-199 - bicarbonate media containing $30 \mathrm{mM}$ fructose. While no changes in lens clarity were apparent in the glucose cultured lenses, distinct time dependent biochemical changes developed with greater differences observed after 48 hours. Therefore, only the 48 hour results which are representative of the early stage of sugar cataract formation are presented. Compared to control lenses cultured in $30 \mathrm{mM}$ fructose media, lenses cultured in $30 \mathrm{mM}$ glucose media demonstrated increased sorbitol levels in the order: AL1576-treated $<$ tolrestat-treated $<$ glucose alone $<$ glucose and mannitol $<$ SDI-treated 
(Fig 1a). The accumulation of sorbitol resulted in a slight increase in lens wet weights due to lens hydration (Kinoshita, 1974; Mizuno et al., 1990). However, lenses cultured in the osmotically compensated medium containing $30 \mathrm{mM}$ glucose and $15 \mathrm{mM}$ mannitol did not increase in wet weight, presumably because the increased osmolarity in the culture medium by mannitol which does not enter the lens counterbalanced the sorbitol-linked osmotic gradient that formed within the lens so that no increase in lens hydration could occur.

Increased sorbitol levels and osmotic stress have been linked to reduced GSH levels in the lens and reduced GSH levels have been reported to be associated with oxidative stress (Lee and Chung, 1999; Mulhern et al., 2006; Obrosova et al., 1999). Compared to the fructosecultured controls, a significant decrease in GSH levels was observed with sorbitol accumulation in lenses cultured in only $30 \mathrm{mM}$ glucose media (Fig 1b). This significant GSH decrease was not observed when lenses were cultured in $30 \mathrm{mM}$ glucose medium containing ARI where sorbitol formation was inhibited. In addition, no significant decrease in GSH levels was observed when lenses were cultured in the osmotically compensated medium containing $30 \mathrm{mM}$ glucose and $15 \mathrm{mM}$ mannitol despite an increase of sorbitol. GSH levels were also not significantly reduced in lenses cultured for 48 hours in glucose medium containing SDI despite the high levels of sorbitol produced by the inhibition of sorbitol metabolism to fructose.

Cataract formation associated with diabetes has also been linked to changes in growth factors and signaling expressions (Srivastava et al., 2005; Zatechka et al., 2003). In the present study, lenses from diabetic rats demonstrated increased expression of the growth factors bFGF and TGF- $\beta$ and this increase did not occur in the lenses from diabetic rats treated with either AL1576 or tolrestat (Fig 2a, 3a). A similar increase in the expression level of these growth factors was observed in lenses cultured in medium containing either 30 $\mathrm{mM}$ glucose alone or $30 \mathrm{mM}$ glucose and SDI (Fig 2b, 3b,). No increase in the expression of these growth factors was observed when lenses were cultured in $30 \mathrm{mM}$ glucose media containing ARIs or with the glucose media containing $15 \mathrm{mM}$ mannitol. To confirm that the induction of bFGF and TGF- $\beta$ were not specifically linked to sorbitol itself, the lenses were also cultured in galactose where similar results were obtained. These studies demonstrate that bFGF and TGF- $\beta$ are synthesized directly within the lens. Furthermore, lenses cultured in the osmotically compensated medium clearly indicate that this induction is not directly due to the increased AR activity or lenticular accumulation of polyol, but to the lens' ability to react to osmotic stress.

The presence of bFGF and TGF- $\beta$ are linked to cellular signaling changes. This was confirmed in the present studies where the increased expression of these growth factors was accompanied by increased signaling of P-Akt, P-ERK1/2, and P-SAPK/JNK both the in vivo diabetic lenses and the in vitro lenses cultured in $30 \mathrm{mM}$ glucose or $30 \mathrm{mM}$ galactose media (Fig 6, Table 2). No induction of signaling was observed in lenses either from diabetic rats treated with ARIs or cultured with ARIs. Again, no increase in signaling was observed in lenses cultured in osmotically compensated medium.

\section{Discussion}

Diabetes mellitus associated hyperglycemia can result in large and sudden increases in aqueous glucose concentrations that, as a result of increased aqueous osmolarity, can dehydrate the lens (Cameron et al., 2001; DiMattio et al., 1981). To diminish potential lens dehydration, sorbitol, an organic osmolyte that is part of the physiological osmoregulatory mechanism, is intracellularly produced to increase lens osmolarity (Chylack et al., 1986). Once formed, the polar nature of sorbitol prevents its rapid removal from within the lens cells. As a result, an osmotic gradient favoring hydration of the sorbitol containing cells is 
formed when hyperglycemia is reduced. This hydration is accentuated by rapid decreases in blood and aqueous glucose levels which can magnify the osmotic differences between the lens cells and aqueous, leading to an additional accumulation of water and hyperopia. Kinoshita was the first to demonstrate the hyperosmotic effects of intracellular sorbitol or galactitol accumulation and to postulate that the resulting cellular swelling can lead to increased membrane permeability and a series of complex biochemical changes associated with sugar cataract formation (Kador and Kinoshita, 1984; Kinoshita, 1974; Kinoshita et al., 1979). The central role of AR in sugar cataract formation has been confirmed by the ability of ARIs to prevent sugar cataract formation in diabetic or galactosemic animals (Kador and Kinoshita, 1984; Kador et al., 2010b; Kinoshita, 1974; Mizuno et al., 1990).

It has also been suggested that hyperglycemia leads to oxidative stress, the depletion of the critical lens antioxidant GSH, and damage to lens transport proteins involved in regulating lens fibers (Crabbe and Goode, 1998; Kador, 2008; Kyselova et al., 2004; Lou, 2003; Lou et al., 1988). The relationship between osmotic and oxidative stress and cataract formation remains undefined with discussions of the relative importance of osmotic versus oxidative stress based on observations that both ARIs and antioxidants can interfere with the onset and progression of sugar cataract formation (Chung et al., 2003). It has also been demonstrated that leaky membranes in the lenses under hyperglycemic conditions prevent ample supplies of precursors for GSH synthesis, resulting in severe loss of GSH (Lou et al., 1988). In addition, sorbitol-induced osmotic stress can induce endoplasmic reticulum (ER) stress that is linked to the initiation of an unfolded protein response (UPR) that generates reactive oxygen species (ROS) (Mulhern et al., 2006; Mulhern et al., 2007). This supports the premise that sorbitol accumulation and osmotic stress precede oxidative stress in sugar cataract formation (Obrosova et al., 1999).

Experimentally, the progression of biochemical changes in sugar cataract formation can be investigated in vitro by culturing lenses in TC-199-bicarbonate media containing reducing sugars such as glucose, galactose or xylose (Obazawa et al., 1974). This method has been used in the present study with ARIs, an SDI, and osmotically compensated media (15 mM mannitol) to gain insight into the importance of osmotic stress on cataract formation. Using $30 \mathrm{mM}$ glucose to simulate the hyperglycemic environment associated with diabetes mellitus resulted in increased sorbitol formation and lowered GSH levels after 48 hours of culture (Fig 1). While this time frame did not result in significant opacity formation, increases occurred both in the expression of the growth factors bFGF and TGF- $\beta$ and activation of signaling components of P-Akt, PERK1/2, and P-SAPK/JNK. A similar increase in growth factor and activation of signaling components were also observed when lenses were cultured in $30 \mathrm{mM}$ glucose plus SDI despite the fact that sorbitol levels in the SDI treated lenses were higher than in those lenses cultured in glucose alone (Fig 1A). Williamson has suggested (Williamson et al., 1993) that excess sorbitol dehydrogenase activity, which utilizes $\mathrm{NAD}^{+}$, can lead to an increase of $\mathrm{NADH} / \mathrm{NAD}^{+}$that can result in a state of oxidative stress "pseudohypoxia", that is similar to that observed in hypoxic tissues in diabetes mellitus. Therefore, inhibition of sorbitol dehydrogenase with an SDI should be beneficial in reducing oxidative stress linked to increased production of NADH. Since a number of in vivo studies have shown that administration of an SDI actually enhances cataract formation in diabetic rats (Geisen et al., 1994; Kador et al., 1998; Obrosova et al., 1999), we were surprised to find that the GSH levels were also not reduced in lenses cultured with SDI at this time point. This suggests that in this initial 48 hour culture period the SDI may contribute in reducing oxidative stress in the lens through the reduction of the "pseudohypoxia". Nevertheless, despite the lack of GSH loss, an increased expression in both the growth factors bFGF and TGF- $\beta$ and signaling though P-Akt, P-ERK1/2, and PSAPK/JNK, were observed in the SDI-treated lenses similar to those lenses cultured in 30 $\mathrm{mM}$ glucose alone. 
The presence of the growth factors bFGF and TGF- $\beta$ and their influence on cellular signaling are also linked to cataract formation (deLongh et al., 2005; Lovicu et al., 2011). Zatecha et al observed in diabetic rats that bFGF accumulates in the vitreous and alters downstream MAPK signaling and the upregulation of phosphorylated ERK and the common stress-associated mitogen-activated protein kinases $\mathrm{p} 38$ and SAPK/JNK. These events were normalized in similar rats treated with the ARI AL1576 (Zatechka et al., 2003).

Subsequently, Kubo et al have reported that mRNA and protein levels of TFG- $\beta$ increase in the lenses of diabetic rats (Kubo et al., 2005).

The present in vivo and in vitro studies both demonstrate that an intracellular induction of bFGF and TGF- $\beta$ and subsequent signaling changes occur immediately after the lens responds to osmotic stress induced by polyol accumulation. Because growth factors were not added to the culture media, the present study also demonstrates that the lenses in response to osmotic stress directly synthesize bFGF and TGF- $\beta$. This is in contrast to many studies where lenses are exposed to an external source of growth factors added to the medium of cultured lenses. It has been proposed that cataract formation many actually be influenced by the aqueous humor because it is a rich "outside" source of growth factors, many of which have been shown to be lens cell mitogens that primarily signal through the MAPK/ERK and PI3-K/Akt pathway (Iyengar et al., 2009). Culturing rat lenses in TGF- $\beta$ actually results in cataract formation, which is exacerbated by the presence of bFGF (Cerra et al., 2003; Lovicu et al., 2004). In these cultured lenses, GSH strongly suppressed TGF- $\beta$-induced opacification and subcapsular plaque formation (Chamberlain et al., 2009). However, in our studies GSH levels did not appear to influence the induction of TGF- $\beta$. Several clinical studies report that aqueous TGF- $\beta 2$ levels are higher in diabetics with or without neovascular glaucoma (Min et al., 2006; Ochiai and Ochiai, 2002). Similarly, bFGF levels are higher in the aqueous of diabetics with macular edema (Jonas and Neumaier, 2007). None of these studies, however, mention cataracts.

In summary, the present studies suggest that AR catalyzes the intracellular accumulation of sorbitol in the lens epithelium and superficial cortical fibers in response to hyperglycemia. While sorbitol accumulation can cause a hyperosmotic imbalance within the sorbitol accumulating cells, it does not directly reduce GSH levels, suggesting glucose-linked oxidation may not occur. When the sorbitol accumulating lens cells finally respond to the osmotic stress, the synthesis of TGF- $\beta$ and bFGF are initiated. At the same time, induction of GRP78 in the lens indicates that ER stress-associated ROS generation occurred. The observed induction of growth factors and signaling suggest that these initially may be protective in nature; however, the prolonged presence of TGF- $\beta$ and signaling perturbation may contribute to the final cataract formation.

\section{Acknowledgments}

This work was supported by NIH grant EY016730.

\section{References}

Aberg MA, Aberg ND, Palmer TD, Alborn AM, Carlsson-Skwirut C, Bang P, Rosengren LE, Olsson T, Gage FH, Eriksson PS. IGF-I has a direct proliferative effect in adult hippocampal progenitor cells. Mol Cell Neurosci. 2003; 24:23-40. [PubMed: 14550766]

Akagi Y, Kador PF, Kinoshita JH. Immunohistochemical localization for aldose reductase in diabetic lenses. Invest Ophthalmol Vis Sci. 1987; 28:163-167. [PubMed: 3100473]

Akagi Y, Tasaka H, Terubayashi H, Kador PF, Kinoshita JH. Aldose reductase localization in rat sugar cataracts. Exerpta Medica Amsterdam. 1988 
Akagi Y, Terubayashi H, Millen J, Kador PF, Kinoshita JH. Aldose reductase localization in dog retinal mural cells. Curr Eye Res. 1986; 5:883-886. [PubMed: 3096638]

Akagi Y, Yajima Y, Kador PF, Kuwabara T, Kinoshita JH. Localization of aldose reductase in the human eye. Diabetes. 1984; 33:562-566. [PubMed: 6427040]

Bradford MM. A rapid and sensitive method for the quantitation of microgram quantities of protein utilizing the principle of protein-dye binding. Anal Biochem. 1976; 72:248-254. [PubMed: 942051]

Brazil DP, Yang ZZ, Hemmings BA. Advances in protein kinase B signalling: AKTion on multiple fronts. Trends Biochem Sci. 2004; 29:233-242. [PubMed: 15130559]

Cameron BD, Baba JS, Cote GL. Measurement of the glucose transport time delay between the blood and aqueous humor of the eye for the eventual development of a noninvasive glucose sensor. Diabetes Technol Ther. 2001; 3:201-207. [PubMed: 11478325]

Cerra A, Mansfield KJ, Chamberlain CG. Exacerbation of TGF-beta-induced cataract by FGF-2 in cultured rat lenses. Mol Vis. 2003; 9:689-700. [PubMed: 14685144]

Chamberlain CG, Mansfield KJ, Cerra A. Glutathione and catalase suppress TGFbeta-induced cataract-related changes in cultured rat lenses and lens epithelial explants. Mol Vis. 2009; 15:895905. [PubMed: 19421408]

Cheng HM, Gonzalez RG. The effect of high glucose and oxidative stress on lens metabolism, aldose reductase, and senile cataractogenesis. Metabolism. 1986; 35:10-14. [PubMed: 3083198]

Chung SS, Ho EC, Lam KS, Chung SK. Contribution of polyol pathway to diabetes-induced oxidative stress. J Am Soc Nephrol. 2003; 14:S233-S236. [PubMed: 12874437]

Chylack LT Jr, Tung W, Harding R. Sorbitol production in the lens: a means of counteracting glucosederived osmotic stress. Ophthalmic Res. 1986; 18:313-320. [PubMed: 3808597]

Crabbe MJ, Goode D. Aldose reductase: a window to the treatment of diabetic complications? Prog Retin Eye Res. 1998; 17:313-383. [PubMed: 9695797]

deLongh RU, Wederell E, Lovicu FJ, McAvoy JW. Transforming growth factor-beta-induced epithelial-mesenchymal transition in the lens: a model for cataract formation. Cells Tissues Organs. 2005; 179:43-55. [PubMed: 15942192]

DiMattio J, Altszuler N, Ellis S, Zadunaisky JA. Glucose transport across ocular barriers of the streptozotocin-diabetic rat. Diabetes. 1981; 30:903-906. [PubMed: 7297778]

Geisen K, Utz R, Grotsch H, Lang HJ, Nimmesgern H. Sorbitol-accumulating pyrimidine derivatives. Arzneimittelforschung. 1994; 44:1032-1043. [PubMed: 7986240]

He X, Hahn P, Iacovelli J, Wong R, King C, Bhisitkul R, Massaro-Giordano M, Dunaief JL. Iron homeostasis and toxicity in retinal degeneration. Prog Retin Eye Res. 2007; 26:649-673. [PubMed: 17921041]

Ibaraki N, Lin LR, Reddy VN. Effects of growth factors on proliferation and differentiation in human lens epithelial cells in early subculture. Invest Ophthalmol Vis Sci. 1995; 36:2304-2312. [PubMed: 7558725]

Ibaraki N, Lin LR, Reddy VN. A study of growth factor receptors in human lens epithelial cells and their relationship to fiber differentiation. Exp Eye Res. 1996; 63:683-692. [PubMed: 9068375]

Iyengar L, Patkunanathan B, McAvoy JW, Lovicu FJ. Growth factors involved in aqueous humourinduced lens cell proliferation. Growth factors. 2009; 27:50-62. [PubMed: 19085197]

Jonas JB, Neumaier M. Vascular endothelial growth factor and basic fibroblast growth factor in exudative age-related macular degeneration and diffuse diabetic macular edema. Ophthalmic Res. 2007; 39:139-142. [PubMed: 17505145]

Kador, PF. Biochemistry of the Lens. Intermediary metabolism and sugar cataract formation. In: E, V.; J, D., editors. Principles and Practice of Ophthalmology. New York: W.B. Saunders Company; 1994. p. 146-167.

Kador, PF. Chapter 18: Ocular Pathology of Diabetes Mellitus Lippincott. Philadelphia: Williams \& Wilkins; 2008.

Kador PF, Hamada T, Reinhardt RA, Blessing K. Effect of an aldose reductase inhibitor on alveolar bone loss associated with periodontitis in diabetic rats. Postgrad Med. 2010a; 122:138-144. [PubMed: 20463423] 
Kador PF, Inoue J, Secchi EF, Lizak MJ, Rodriguez L, Mori K, Greentree W, Blessing K, Lackner PA, Sato $\mathrm{S}$. Effect of sorbitol dehydrogenase inhibition on sugar cataract formation in galactose-fed and diabetic rats. Exp Eye Res. 1998; 67:203-208. [PubMed: 9733586]

Kador PF, Kinoshita JH. Diabetic and galactosaemic cataracts. Ciba Found Symp. 1984; 106:110-131. [PubMed: 6439498]

Kador PF, Lee JW, Fujisawa S, Blessing K, Lou MF. Relative importance of aldose reductase versus nonenzymatic glycosylation on sugar cataract formation in diabetic rats. J Ocul Pharmacol Ther. 2000; 16:149-160. [PubMed: 10803425]

Kador PF, Webb TR, Bras D, Ketring K, Wyman M. Topical KINOSTAT ameliorates the clinical development and progression of cataracts in dogs with diabetes mellitus. Vet Ophthalmol. 2010b; 13:363-368. [PubMed: 21182720]

Kampmeier J, Baldysiak-Figiel A, de Jong-Hesse Y, Lang GK, Lang GE. Effect of growth factors on proliferation and expression of growth factor receptors in a human lens epithelial cell line. J Cataract Refract Surg. 2006; 32:510-514. [PubMed: 16631066]

Kinoshita JH. Mechanisms initiating cataract formation. Proctor Lecture. Invest Ophthalmol. 1974; 13:713-724. [PubMed: 4278188]

Kinoshita JH, Fukushi S, Kador P, Merola LO. Aldose reductase in diabetic complications of the eye. Metabolism. 1979; 28:462-469. [PubMed: 45423]

Kubo E, Singh DP, Akagi Y. Gene expression profiling of diabetic and galactosaemic cataractous rat lens by microarray analysis. Diabetologia. 2005; 48:790-798. [PubMed: 15761720]

Kyselova Z, Stefek M, Bauer V. Pharmacological prevention of diabetic cataract. J Diabetes Complications. 2004; 18:129-140. [PubMed: 15120709]

Lee AY, Chung SS. Contributions of polyol pathway to oxidative stress in diabetic cataract. Faseb J. 1999; 13:23-30. [PubMed: 9872926]

Lou MF. Redox regulation in the lens. Prog Retin Eye Res. 2003; 22:657-682. [PubMed: 12892645]

Lou MF, Dickerson JE Jr. Protein-thiol mixed disulfides in human lens. Exp Eye Res. 1992; 55:889896. [PubMed: 1486943]

Lou MF, Dickerson JE Jr, Garadi R, York BM Jr. Glutathione depletion in the lens of galactosemic and diabetic rats. Exp Eye Res. 1988; 46:517-530. [PubMed: 3133235]

Lovicu FJ, McAvoy JW, de Iongh RU. Understanding the role of growth factors in embryonic development: insights from the lens. Philos Trans R Soc Lond B Biol Sci. 2011; 366:1204-1218. [PubMed: 21402581]

Lovicu FJ, Steven P, Saika S, McAvoy JW. Aberrant lens fiber differentiation in anterior subcapsular cataract formation: a process dependent on reduced levels of Pax6. Invest Ophthalmol Vis Sci. 2004; 45:1946-1953. [PubMed: 15161862]

Min SH, Lee TI, Chung YS, Kim HK. Transforming growth factor-beta levels in human aqueous humor of glaucomatous, diabetic and uveitic eyes. Korean J Ophthalmol. 2006; 20:162-165. [PubMed: 17004630]

Mizuno A, Toshima S, Mori Y. Confirmation of lens hydration by Raman spectroscopy. Exp Eye Res. 1990; 50:647-649. [PubMed: 2115454]

Mulhern ML, Madson CJ, Danford A, Ikesugi K, Kador PF, Shinohara T. The unfolded protein response in lens epithelial cells from galactosemic rat lenses. Invest Ophthalmol Vis Sci. 2006; 47:3951-3959. [PubMed: 16936110]

Mulhern ML, Madson CJ, Kador PF, Randazzo J, Shinohara T. Cellular osmolytes reduce lens epithelial cell death and alleviate cataract formation in galactosemic rats. Mol Vis. 2007; 13:13971405. [PubMed: 17768385]

Obazawa H, Merola LO, Kinoshita JH. The effects of xylose on the isolated lens. Invest Ophthalmol. 1974; 13:204-209. [PubMed: 4855947]

Obrosova IG, Fathallah L, Lang HJ. Interaction between osmotic and oxidative stress in diabetic precataractous lens: studies with a sorbitol dehydrogenase inhibitor. Biochem Pharmacol. 1999; 58:1945-1954. [PubMed: 10591149]

Ochiai Y, Ochiai H. Higher concentration of transforming growth factor-beta in aqueous humor of glaucomatous eyes and diabetic eyes. Jpn J Ophthalmol. 2002; 46:249-253. [PubMed: 12063033]

Exp Eye Res. Author manuscript; available in PMC 2013 August 01. 
Pearson G, Robinson F, Beers Gibson T, Xu BE, Karandikar M, Berman K, Cobb MH. Mitogenactivated protein (MAP) kinase pathways: regulation and physiological functions. Endocr Rev. 2001; 22:153-183. [PubMed: 11294822]

Ramana KV, Friedrich B, Bhatnagar A, Srivastava SK. Aldose reductase mediates cytotoxic signals of hyperglycemia and TNF-alpha in human lens epithelial cells. Faseb J. 2003; 17:315-317. [PubMed: 12490536]

Schneider R, Jensen SA, Whiteman P, McCullagh JS, Redfield C, Handford PA. Biophysical characterisation of fibulin-5 proteins associated with disease. J Mol Biol. 2010; 401:605-617. [PubMed: 20599547]

Shiono T, Kador PF, Kinoshita JH. Ornithine accumulation and metabolism in rat lens. Exp Eye Res. 1985; 40:421-429. [PubMed: 3933991]

Simard-Duquesne N, Greselin E, Dubuc J, Dvornik D. The effects of a new aldose reductase inhibitor (tolrestat) in galactosemic and diabetic rats. Metabolism. 1985; 34:885-892. [PubMed: 3930915]

Srivastava SK, Ramana KV, Bhatnagar A. Role of aldose reductase and oxidative damage in diabetes and the consequent potential for therapeutic options. Endocr Rev. 2005; 26:380-392. [PubMed: 15814847]

Williamson JR, Chang K, Frangos M, Hasan KS, Ido Y, Kawamura T, Nyengaard JR, Enden Mvd, Kilo C, Tilton RG. Hyperglycemic pseudohypoxia and diabetic complications. Diabetes. 1993; 42:801-813. [PubMed: 8495803]

Yadav UC, Ighani-Hosseinabad F, van Kuijk FJ, Srivastava SK, Ramana KV. Prevention of posterior capsular opacification through aldose reductase inhibition. Invest Ophthalmol Vis Sci. 2009; 50:752-759. [PubMed: 19011011]

Zatechka DS Jr, Kador PF, Garcia-Castineiras S, Lou MF. Diabetes can alter the signal transduction pathways in the lens of rats. Diabetes. 2003; 52:1014-1022. [PubMed: 12663474]

Zatechka SD Jr, Lou MF. Studies of the mitogen-activated protein kinases and phosphatidylinositol-3 kinase in the lens. 1. The mitogenic and stress responses. Exp Eye Res. 2002; 74:703-717. [PubMed: 12126944]

Zhang Z, Yao K, Jin C. Apoptosis of lens epithelial cells induced by high concentration of glucose is associated with a decrease in caveolin-1 levels. Mol Vis. 2009; 15:2008-2017. [PubMed: 19816600] 

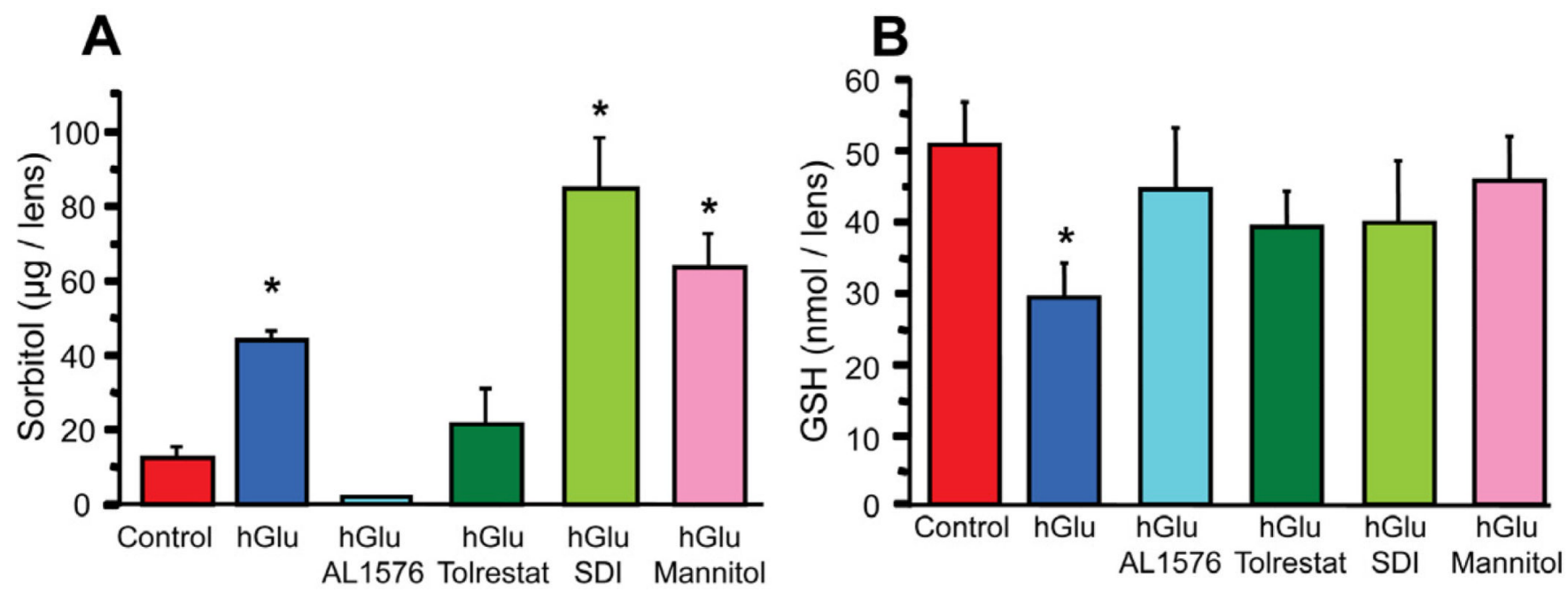

Figure 1.

Sorbitol (A) and reduced glutathione levels (B) in lenses cultured for 48 hours in TC-199 bicarbonate media supplemented with either $30 \mathrm{mM}$ fructose (control) or $30 \mathrm{mM}$ glucose (hGlu) with/without the aldose reductase inhibitors AL1576 or tolrestat, or the sorbitol dehydrogenase inhibitor CP-166,572 (SDI), or $30 \mathrm{mM}$ glucose and $15 \mathrm{mM}$ mannitol (hGlu Mannitol). Mean \pm SEM; $n=4$. * significantly different $(p \leq 0.05)$ from control. 


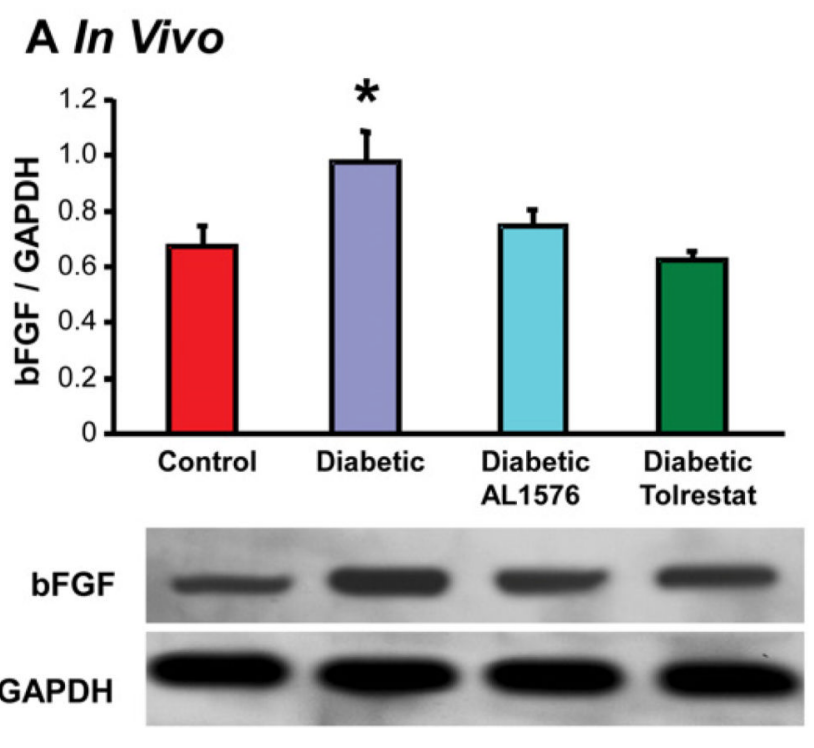

\section{B In Vitro}

Figure 2.

Comparison of expression levels of the growth factor bFGF normalized to GAPDH in (A) lenses from 10 week diabetic rats treated with/without AL1576 or tolrestat and age matched nondiabtic rats and (B) in lenses cultured for 48 hours in TC-199 - bicarbonate media supplemented with either $30 \mathrm{mM}$ fructose (control) or $30 \mathrm{mM}$ glucose (hGlu) with/without the aldose reductase inhibitors AL1576 or tolrestat, or the sorbitol dehydrogenase inhibitor CP-166,572 (SDI), or $30 \mathrm{mM}$ glucose and $15 \mathrm{mM}$ mannitol (hGlu Mannitol). Mean \pm SEM; $\mathrm{n}=4-7$. * significantly different $(\mathrm{p} \leq 0.05)$ from control. 


\section{A In Vivo}

\section{B In Vitro}

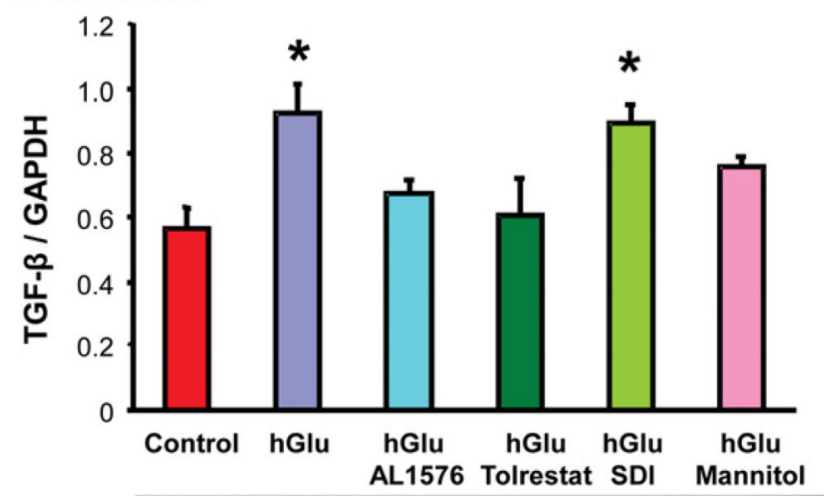

TGF- $\beta$

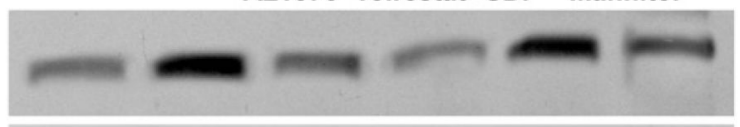

\section{GAPDH}

Figure 3.

Comparison of expression levels of the growth factor TGF- $\beta$ normalized to GAPDH in (A) lenses from 10 week diabetic rats treated with/without AL1576 or tolrestat and age matched nondiabtic rats and (B) in lenses cultured for 48 hours in TC-199 - bicarbonate media supplemented with either $30 \mathrm{mM}$ fructose (control) or $30 \mathrm{mM}$ glucose (hGlu) with/without the aldose reductase inhibitors AL1576 or tolrestat, or the sorbitol dehydrogenase inhibitor CP-166,572 (SDI), or $30 \mathrm{mM}$ glucose and $15 \mathrm{mM}$ mannitol (hGlu Mannitol). Mean \pm SEM; $\mathrm{n}=4-7 . *$ significantly different $(\mathrm{p} \leq 0.05)$ from control. 


\section{A In Vivo}

\section{B In Vitro}

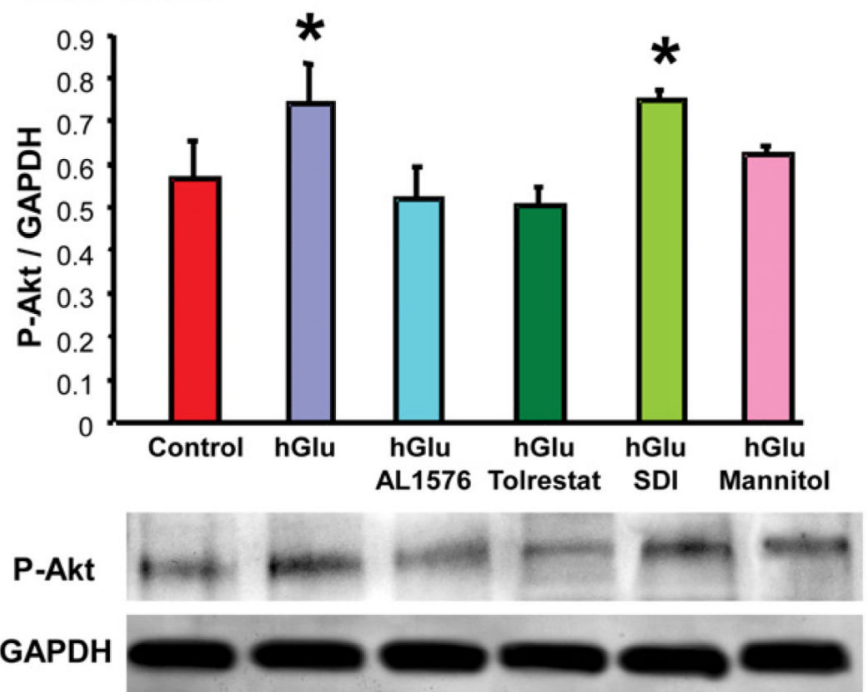

Figure 4.

Comparison of expression levels of phosphorylated-Akt normalized to GAPDH in (A) lenses from 10 week diabetic rats treated with/without AL1576 or tolrestat and age matched nondiabtic rats and (B) in lenses cultured for 48 hours in TC-199 - bicarbonate media supplemented with either $30 \mathrm{mM}$ fructose (control) or $30 \mathrm{mM}$ glucose (hGlu) with/without the aldose reductase inhibitors AL1576 or tolrestat, or the sorbitol dehydrogenase inhibitor CP-166,572 (SDI), or $30 \mathrm{mM}$ glucose and $15 \mathrm{mM}$ mannitol (hGlu Mannitol). Mean \pm SEM; $\mathrm{n}=4-7$. $*$ significantly different $(\mathrm{p} \leq 0.05)$ from control. 


\section{A In Vivo}

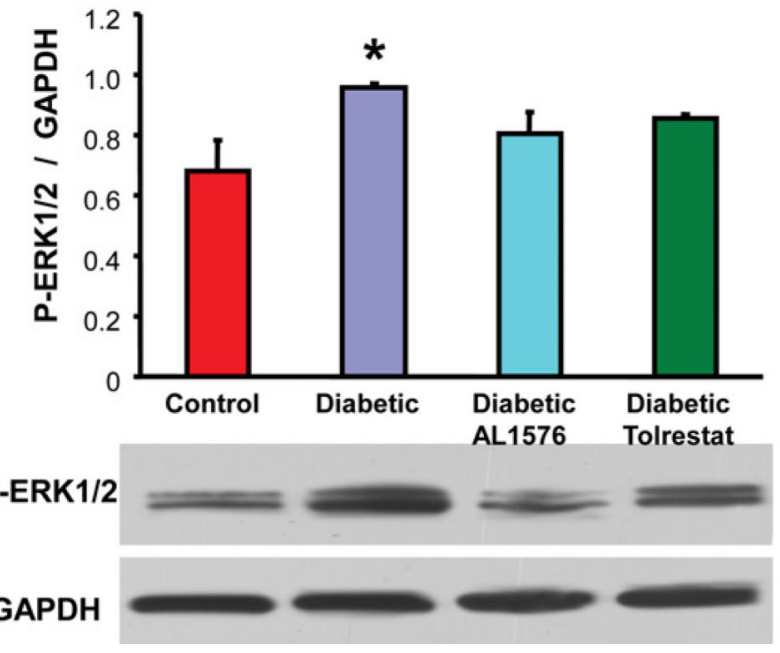

\section{B In Vitro}

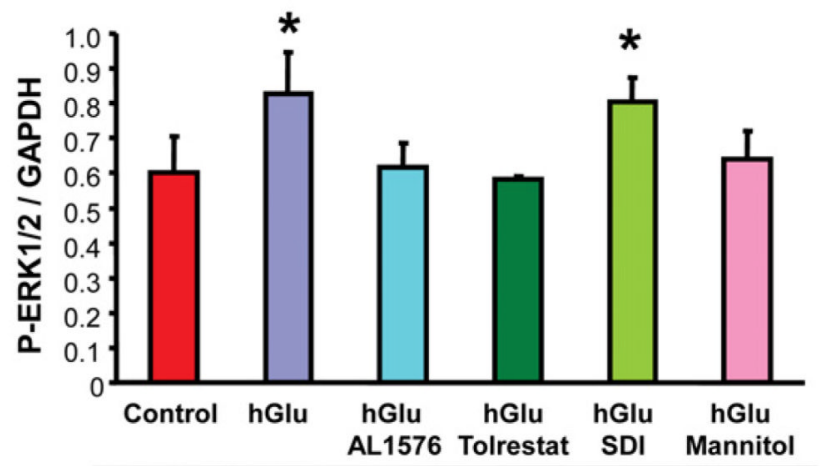

P-ERK1/2

GAPDH

Figure 5.

Comparison of expression levels of phosphorylated ERK1/2 normalized to GAPDH in (A) lenses from 10 week diabetic rats treated with/without AL1576 or tolrestat and age matched nondiabtic rats and (B) in lenses cultured for 48 hours in TC-199 - bicarbonate media supplemented with either $30 \mathrm{mM}$ fructose (control) or $30 \mathrm{mM}$ glucose (hGlu) with/without the aldose reductase inhibitors AL1576 or tolrestat, or the sorbitol dehydrogenase inhibitor CP-166,572 (SDI), or $30 \mathrm{mM}$ glucose and $15 \mathrm{mM}$ mannitol (hGlu Mannitol). Mean \pm SEM; $\mathrm{n}=4-7$. ${ }^{*}$ significantly different $(\mathrm{p} \leq 0.05)$ from control. 


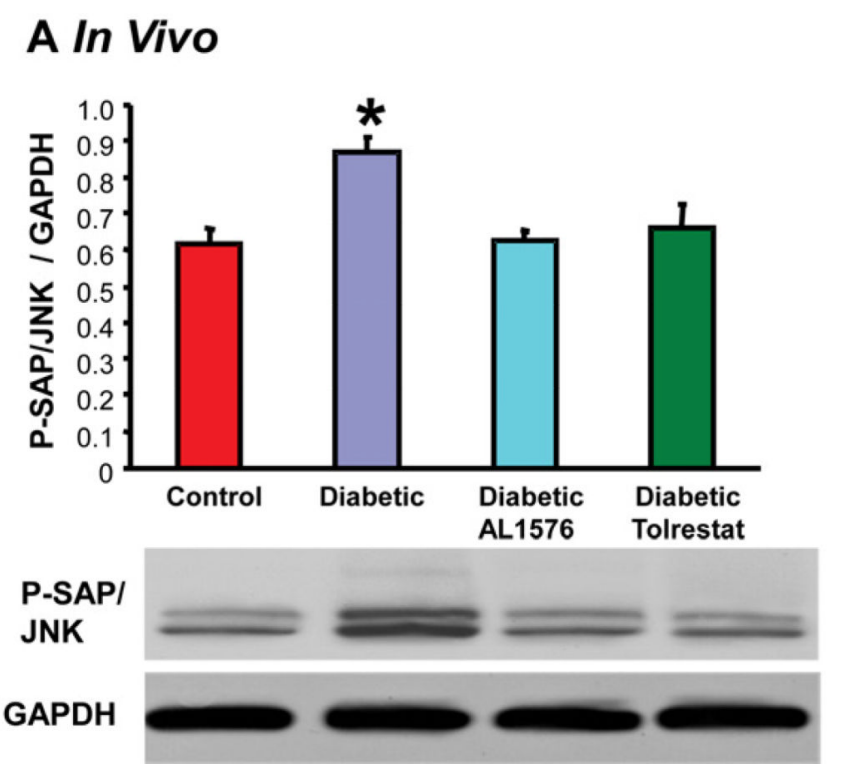

\section{B In Vitro}

Figure 6.

Comparison of expression levels of phosphorylated SAPK/JNK normalized to GAPDH in (A) lenses from 10 week diabetic rats treated with/without AL1576 or tolrestat and age matched nondiabtic rats and (B) in lenses cultured for 48 hours in TC-199 - bicarbonate media supplemented with either $30 \mathrm{mM}$ fructose (control) or $30 \mathrm{mM}$ glucose (hGlu) with/ without the aldose reductase inhibitors AL1576 or tolrestat, or the sorbitol dehydrogenase inhibitor CP-166,572 (SDI), or $30 \mathrm{mM}$ glucose and $15 \mathrm{mM}$ mannitol (hGlu Mannitol). Mean \pm SEM; $n=4-7$. * significantly different $(\mathrm{p} \leq 0.05)$ from control. 


\section{Table 1}

Lens sorbitol and reduced glutathione levels from streptozotocin-induced diabetic rats fed diet with/without the aldose reductase inhibitors AL1576 or tolrestat for 10 weeks or their age-matched nondiabetic controls. Mean \pm SEM; $n=4$.

\begin{tabular}{|c|c|c|}
\hline Group & $\begin{array}{c}\text { Sorbitol } \\
(\boldsymbol{\mu g} / \mathrm{lens})\end{array}$ & $\begin{array}{c}\text { GSH } \\
(\mathbf{n m o l} / \mathrm{lens})\end{array}$ \\
\hline Control & $5.1 \pm 5.1$ & $54.1 \pm 1.0$ \\
\hline Diabetic & $151.9 \pm 21.3^{*}$ & $19.5 \pm 1.6^{*}$ \\
\hline Diabetic + AL1576 & $12.7 \pm 2.6$ & $51.0 \pm 6.9$ \\
\hline Diabetic + Tolrestat & $19.6 \pm 7.7$ & $39.9 \pm 3.0^{*}$ \\
\hline
\end{tabular}

* significantly different ( $\leq \leq 0.05)$ from control. 


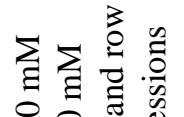

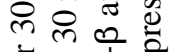

tे

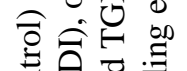

泀氞焉

过志

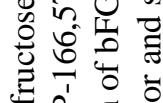

$\sum_{0}^{1}$ 它

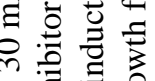

可寻.

矛范

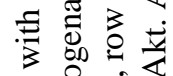

월을

类

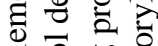

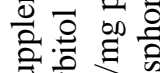

के 흉

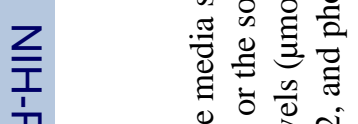

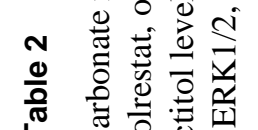

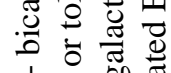

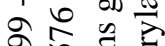

을

记专范

$\Xi$ ㅎํ음

壱:

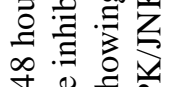

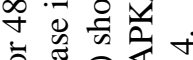

过苛究

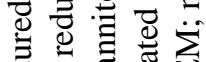

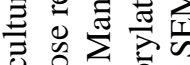

o 음 +1

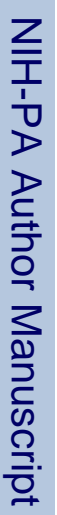

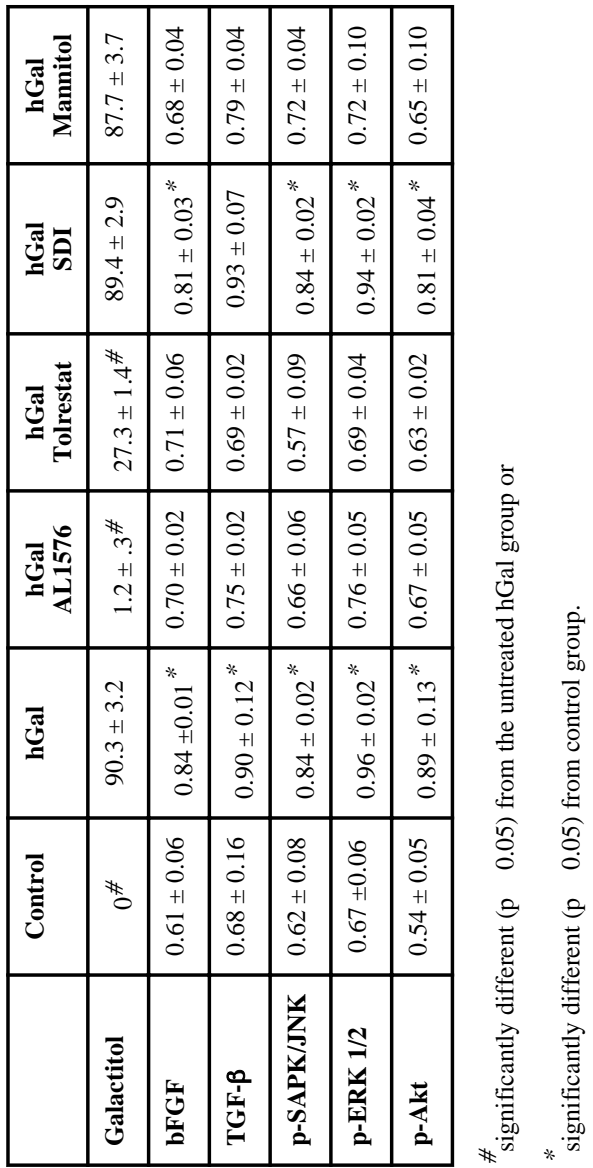

Exp Eye Res. Author manuscript; available in PMC 2013 August 01. 